\section{Pengelolaan Dana Lembaga Filantropi Islam Dalam Pengembangan Ekonomi U mat}

\author{
Deden G andana M adjakusumah, Udin Saripudin* \\ Pascasarjana Universitas Islam Bandung
}

\begin{abstract}
A bstract
Purpose: This paper aims to gather information about the management of ZISWAF through literature review. Methods: This study uses a qualitative approach to describe findings from facts and reality in society with a phenomology approach. A literature review and documentation are conducted to collect the data. Finding: ZISWAF funds can be maximized for the economic development of the people, but currently these funds are still much engaged in the area of social service activities, charity assistance, compensation for orphans, $M$ adrasah development, and others. Even tend to ignore the interests of other M uslims such as legal aid, child protection, public policy advocacy, women's empowerment, and several other important agendas, still lacking support from the utilization of philanthropic funds in addition to efforts to find out the potential of Islamic philanthropy and its impact on the economic development of the people, especially poor people or poor people.
\end{abstract}

\begin{abstract}
A bstrak
Tujuan- Tulisan ini bertujuan untuk menggali informasi mengenai pengelolaan ZISWAF. Metode: Penelitian ini menggunakan pendekatan kualitatif untuk mendiskripsikan penemuan dari fakta dan realita yang ada di masyarakat dengan pendekatan fenomologi. Studi pustaka dan dokumentasi dilakukan untuk mengumpulkan data. Temuan: Dana ZISWAF dapat dimaksimalkan untuk pengembangan ekonomi umat, namun saat ini dana tersebut masih banyak bergerak dalam wilayah kegiatan bakti sosial, bantuan karitas, santunan anak yatim, pembangunan Madrasah dan lainnya. Bahkan cenderung mengabaikan kepentingan umat Islam lainnya seperti, bantuan hukum, perlindungan anak, advokasi kebijakan publik, pemberdayaan perempuan dan beberapa agenda penting lainnya, masih kurang mendapatkan support dari pendayahgunaan dana filantropi disamping upaya ingin mengetahui potensi filantropi Islam dan dampaknya bagi pengembangan ekonomi umat, terutama masyarakat miskin atau kaum dhuafa.
\end{abstract}

Pedoman Sitasi: Madjakusumah, D. G \& Saripudin. (2020). Pengelolaan Dana Lembaga Filantropi Islam Dalam Pengembangan Ekonomi Umat. SERAMBI: Jurnal Ekonomi $M$ anajemen dan Bisnis Islam, 2(1), 41 - 50

D 0I: https:/ / doi.org/ 10.36407/ serambi.v2i1.151

\section{SERAM BI}

Received 12 Feb 2020

Revised 23 Mar 2020

Accepted 25 A pr 2020

Online first 30 Apr 2020

\section{Paper type}

Research paper

Email : udin_saripudin27@yahoo.co. id

Keywords: Islamic Philanthropy, Economic Development of the Community

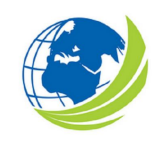

SERAMBI : Jurnal Ekonomi dan Bisnis Islam, Vol 2, No.1, 2020, pp. 41-50

elSSN 2685-9904 


\section{Pendahuluan}

Kedermawanan umat islam menyimpan potensi yang sangat besar dalam pengembangan filantropi islam untuk mengatasi masalah ekonomi umat, karena kehidupan ekonomi umat belum sungguh sungguh mencerminkan kesejahteraan sebagaimana yang diamanatkan dalam Undang Undang Dasar 1945 dan Ajaran Agama Islam. Dengan adanya filantropi umat islam yaitu kedermawanan sebagai suatu kesadaran untuk memberi, merupakan praktik filantropi Islam yang sudah lama terbangun sejak periode awal Islam, dan berkembang menjadi salah satu praktik yang mengemuka seiring dengan perkembangan Islam. Dalam ajaran islam, filantropi adalah perbuatan yang sangat mulia, bagian utama dari ketaqwaan seorang muslim sebagai perbuatan yang akan mengundang keberkahan, rakhmat dan pertolongan Allah SWT .

Indonesia merupakan negara yang mayoritas penduduknya muslim, menjadikan filantropi islam mempunyai potensi yang sangat besar dalam mewujudkan pengembangan ekonomi umat. Apalagi dengan adanya zakat, infaq, shadaqah, dan wakaf (ZISWAF) yang didukung oleh fatwa-fatwa ulama serta peraturan dan perundang-undangan di Indonesia, maka peran lembaga-lembaga filantropi islam dalam pengumpulan dan pengalokasian dana ZISWAF sudah seharusnya dapat memberi manfaat bagi masyarakat luas dalam pengembangan ekonomi umat (Saripudin, 2016). Seperti halnya dana lembaga filantropis Islam yang didapat dari zakat sangat berpotensi memajukan ekonomi umat karena ajaran Islam memiliki konsep zakat sebagai bentuk kepedulian orang kaya kepada orang miskin yang tidak mampu, pemberian zakat kepada orang miskin pada hakikatnya dimaksudkan bukan saja memperkecil jurang kesenjangan antara orang kaya dan orang miskin terlebih untuk mengangkat mereka terbebas dari kemiskinan, dan mencegah mereka dari hidup kelaparan dan kesengsaraan, bahkan lebih jauh dari itu untuk merubah si miskin menjadi kaya, merubah mustahik menjadi muzaki

Pesan Rasulullah SAW "Aghunum fi hadza al-yaum" ( bikin kaya para fakir miskin itu dengan harta zakat yang terkumpul pada hari ini). Zakat adalah bagian dari harta dengan persyaratan tertentu yang Allah SWT mewajibkan pemiliknya untuk diserahkan kepada mustahiq. Asy Syaukani dalam Hasbi Ash Shiddiqie (2007) mengatakan bahwa: "Zakat yaitu memberi suatu bagian harta yang sudah sampai nishab kepada orang fakir dan sebagainya". Selanjutnya menurut hadist yang berasal dari Ibnu Abbas dalam Daud Ali (2006) dikemukakan bahwa: “ Ketika nabi Muhammad mengutus Mu'az bin jabal ke Yaman, Nabi menegaskan bahwa zakat adalah harta yang diambil dari orang-orang kaya untuk disampaikan kepada yang berhak menerimananya, antara lain fakir dan miskin". Hal ini menunjukan filantropi Islam dapat menjadi modal sosial untuk membangun civil society yang kokoh dan bermartabat kearah terbangunnya ekonomi umat. Karena tradisi ini bukan hanya mencerminkan suatu bentuk ketaatan dalam beragama, melainkan juga menjadi bagian tak terpisahkan dari perkembangan masyarakat muslim di sisi sosial,ekonomi dan budaya masyarakat.

Di Indonesia, praktek filantropi Islam telah berakar kuat dalam tradisi masyarakat Indonesia yakni dalam bentuk zakat, infaq, shadaqoh dan wakaf (ZISWAF), terutama dalam situasi makin melebarnya kesenjangan masyarakat kaya dan miskin serta berbagai bencana alam yang datang silih berganti telah menggairahkan dunia filantropi di Indonesia. Aktifitas lembagalembaga sosial marak luar biasa, aliran bantuan uang dan barang pun tercatat mencapai triliunan rupiah. Khusus untuk filantropi Islam, lembaga-lembaga Filantropi Islam hadir dan ditujukan untuk menjawab masalah kemiskinan. Namun demikian, hanya sedikit yang mencoba mengatasi masalah ini dari akarnya. Hasil riset yang dilakukan BAZNAS dan FEM IPB dalam Salman Nashiir (2017) mengemukakan bahwa meskipun potensi potensi zakat nasional mencapai 3,4\% dari PDB atau sebesar 217 triliun, namun angka tersebut berbanding terbalik dengan 
pengumpulan dana wakaf yang dihimpun yaitu hanya sebesar $1 \%$ atau sekitar 2,6 triliun. Kondisi yang sama juga terjadi pada sektor wakaf yang baru dapat menghimpun dana wakaf 147 miliar dari potensi pertahun 6 triliun. Studi yang dilakukan CSRC UIN Jakarta (2015) memberikan kesimpulan serupa, yaitu meskipun dana dana filantropi yang disumbangkan oleh masyarakat Muslim Indonesia saat ini sudah mencapai angka 19,3 Trilyun/ tahun, namun dana itu dianggap belum maksimal untuk mengurangi kemiskinan, dan bahkan menciptakan ketergantungan masyakarat. Aset wakaf yang bernilai 590 trilyun berdasarkan riset mereka ternyata $80 \%$ digunakan untuk masjid dan pekuburan.

Berdasarkan hal tersebut dapat dilihat bahwa potensi Indonesia dalam pengelolaan dana lembaga filantropi islam sangat besar tetapi belum sesuai dengan harapan untuk dapat berkontribusi dalam pengembangan ekonomi umat karena faktor manajemen lembaga filantropi islam terkait kurang efektifnya pengelolaan dana lembaga filantropi islam, padahal dengan makin banyaknya lembaga filantropi islam di Indonesia, seharusnya dapat lebih tersosialisasikan nilai-nilai filantropi islam kepada masyarakat dan kepentingannya bagi pengembangan ekonomi umat dengan harapan dapat menjadi pendorong pengumpulan dana filantropi islam bagi pengembangan ekonomi umat dan fenomena inilah yang menjadikan pentingnya pembahasan makalah tentang pengelolaan dana lembaga filantropi Islam dalam pengembangan ekonomi umat.

Sejalan dengan fakta dilapangan tersebut, kajian mengenai filantropi Islam juga masih relative terbatas. Kasdi (2016) melakukan penelitian mengenai ZISWAF pada pengelola BMT seKabupaten Demak menunjukkan bahwa ZISWAF yang dikelola oleh BMT Kabupaten Demak menggunakan tiga sistem yaitu sistem pengelolaan satu arah, sistem pengelolaan umpan Balik (feed back), dan dengan sistem pilot project. Model pemberdayaan ZISWAF yang dilakukan oleh pengelola BMT melalui pemberdayaan sosial dengan cara menyalurkan dana ke fakir miskin secara langsung, pemberdayaan dalam rangka pengembangan sumber daya manusia, dan dengan model pemberdayaan ekonomi dengan mudharabah muqayyadah, wadi' ah muqayyadah dan pemberdayaan dengan pinjaman lunak tanpa bagi hasil. Studi lain dilakukan oleh Setyanto (2016) Penelitian ini menelaah tentang tradisi persenan bagi pedagang pracangan di pasar Legi Songgolangit Ponorogo dalam perspektif filantropi Islam menemukan bahwa penerapan hal ini lebih condong kepada pemberian hibah. selain mempunyai nilai ibadah juga menjadi sarana promosi bagi pedagang pracangan yang bisa menambah loyalitas pembeli dan berkembangnya penjualan produk. al-Mubarok dan Muslim (2020) memberikan kesimpulan bahwa dengan filantropi Islam, kekayaan dapat dapat disalurkan ke Fakir, miskin, Dhuafa, anak yatim, dan siapa yang berhak menerimanya, dan hal ini dapat meningkatkan kesejahteraan mereka di bidang ekonomi, kesehatan dan pendidikan. Studi terbaru yang dilakukan oleh Sudiyo dan Fitriani (2020) memberikan kesimpulan bahwa secara garis besar empat lembaga filantropi Islam yang diteliti memiliki visi-misi keummatan yang tujuannya membawa kepada kondisi masyarakat yang berdaya, dan itu harus diawali dengan program fundraising yang efektif. Ditemukan bahwa strategi fundraising yang dijalankan adalah pembiayaan langsung dan pembiayaan tidak langsung.

Penelitian ini bertujuan untuk memperoleh infomasi lebih mendalam mengenai pengelolaan dana lembaga filantropi islam dalam pengembangan ekonomi umat. Hal ini masih diperlukan mengingat besarnya potensi Indonesia dalam pengelolaan dana lembaga filantropi islam, namun yang terjadi di lapangan belum sesuai dengan harapan untuk dapat berkontribusi dalam pengembangan ekonomi umat. Oleh karenanya, studi ini lebih ditujukan untuk mempelajari faktor manajemen lembaga filantropi islam dan sebab kurang efektifnya 
pengelolaan dana lembaga filantropi islam. Studi ini dapat bermafaat sebagai pendorong pengumpulan dana filantropi islam bagi pengembangan ekonomi umat, dan landasan studi berikutnya pada isu yang serupa.

\section{Metode}

Penelitian ini menggunakan pendekatan kualitatif untuk mendiskripsikan penemuan dari fakta dan realita yang ada di masyarakat dengan pendekatan fenomologi. Studi literature dan dokumentasi dilakukan untuk mengumpulkan data.

\section{Pembahasan}

Pengel olaan Dana Lembaga Filantropi Islam

Pengelolaan dana lembaga filantropi islam diperlukan adanya Manajemen yang dapat memegang peranan sangat penting dalam pengelolaan dana lembaga filantropi islam karena menurut Athoillah (2010) bahwa "manajemen berasal dari kata to manage yang artinya mengatur, mengurus dan mengelola". A rtinya ada pengaturan, pengurusan dan pengelolaan dana lembaga filantropi islam dan menurut Terry dalam Hasibuan (2014) mendefinisikan manajemen sebagai suatu proses yang khas yang terdiri dari tindakan-tindakan perencanaan, pengorganisasian, pengarahan, dan pengendalian untuk menentukan dan mencapai sasaransasaran organisasi yang telah ditetapkan dengan cara pemanfaatan sumber daya manusia serta sumber sumber lain secara maksimal. Dengan kata lain dalam kaitannya dengan pengelolaan dana lembaga filantropi islam terdapat adanya aktivitas- aktivitas khusus yang merupakan bagian dari suatu proses pengelolaan dana lembaga filantropi islam yang dilakukan untuk mencapai tujuan dalam pengembangan ekonomi umat dengan bantuan sumber daya manusia dan sumber daya lainnya.

Manajemen berorientasi pada proses (process oriented) yang berarti bahwa manajemen dalam pengelolaan dana lembaga filantropi islam membutuhkan sumber daya lain disamping sumber daya manusia yaitu , pengetahuan, dan keterampilan agar aktivitas menjadi lebih efektif atau dapat menghasilkan tindakan dalam mencapai kesuksesan. Oleh sebab itu, tidak akan ada organisasi yang akan sukses apabila tidak menggunakan manajemen yang baik. Terry (dalam Hasibuan, 2104) memberikan tiga alasan diperlukan tujuan manajemen yaitu:" ( a ). Untuk mencapai tujuan organisasi dan pribadi. (b). Untuk menjaga keseimbangan antara tujuan yang saling bertentangan. (c.) Untuk mencapai efisiensi, dan efektifitas". Fungsi Manajemen Menurut Terry ada empat fungsi utama manajemen, yang dalam dunia manajemen dikenal sebagai P O A C, yaitu planning (perencanaan), organizing ,(pengorganisasian), actuating (penggerakan atau pengarahan) dan controlling (pengendalian).

Dengan adanya konsep manajemen tersebut sudah saatnya pengelolaan dana lembaga filantropi islam didekati dengan menentukan Visi, Misi,Tujuan dan Sasaran lembaga pengelola dana filantropi islam dan mengoperasional kannya melalui fungsi fungsi manajemen mulai dari adanya planning (perencanaan), organizing ,(pengorganisasian), actuating (penggerakan atau pengarahan) sampai controlling (pengendalian).

Konten Visi, Misi,Tujuan dan Sasaran dengan melihat pada filantropi yang diartikan sebagai rasa kecintaan kepada manusia dalam bentuk pemberian derma kepada orang lain yang dianggap membutuhkan (Ilchman, 2006). Pendapat lain dikemukakan oleh Klein (2001) menjelaskan bahwa filantropi sebagai konseptualisasi dari praktik pemberian sumbangan sukarela (voluntary giving), penyediaan layanan sukarela (voluntary services) dan asosiasi sukarela (voluntary association) secara suka rela untuk membantu pihak lain yang membutuhkan sebagai 
ekspresi rasa cinta. Filantropi dalam arti pemberian derma biasa juga disamakan dengan istilah karitas (charity).

Praktik filantropi dalam tradisi Islam melalui zakat, infak, sedekah, dan wakaf perlu diadopsi dalam penyusunan Visi, Misi, Tujuan dan sasaran dalam pengelolaan dana lembaga filantropi (Abu Zahrah, 2005). Istilah ini dapat memberikan makna bahwa nilai kedermawanan Islam dapat menjangkau isu-isu sosial kemasyarakatan yang lebih luas. Filantropi tidak hanya dilihat dari sisi tradisional, seperti fikih, dan kajian nilai-nilai islam lainnya, akan tetapi dapat dapat mengaitkan berbagai isu terkini seperti masalah kemiskinan, keadilan sosial, kesejahteraan umat, masyarakat madani, kebijakan publik, tata kel ola yang baik dan manajemen yang profesional. Hal ini menunjukkan bahwa nilai-nilai Islam memiliki relevansi dengan sosial kemasyarakatan sekaligus dapat menjawab permasalahan yang terjadi di saat sekarang.

Islam menganjurkan seorang Muslim untuk berfilantropi agar harta kekayaan tidak hanya berputar di antara orang-orang kaya (QS. al-Hasyr: 7). Dalam konteks ini, al- Qur'an sering menggunakan istilah zakat, infak dan sedekah yang mengandung pengertian berderma. Kedermawanan dalam Islam mencakup dimensi-dimensi kebaikan secara luas seperti zakat, infak, sedekah, dan wakaf merupakan istilah istilah yang menunjukkan bentuk resmi filantropi Islam. Sistem filantropi Islam ini dirumuskan oleh para fuqaha dengan mengambil rujukan pada al-Qur'an dan hadits Nabi mengenai ketentuan terperind, seperti jenis-jenis harta, kadar minimal, jumlah, serta aturan yang lainnya. Al-Qur'an tidak mengintrodusir istilah zakat, tetapi sedekah. Namun, pada tatanan diskursus penggunaan istilah zakat, infak dan sedekah terkadang juga mengandung makna yang khusus dan juga digunakan secara berbeda (QS. at-Taubah: 60).

Zakat sering diartikan sebagai pengeluaran harta yang sifatnya wajib dan salah satu dari rukun Islam serta berdasarkan pada perhitungan tertentu. Infak sering merujuk kepada pemberian yang bukan zakat, yang kadangkala jumlahnya lebih besar atau lebih kedi dari zakat dan biasanya untuk kepentingan umum. Misalnya bantuan untuk mushalla, masjid, madrasah dan pondok pesantren. Sedekah biasanya mengacu pada derma yang kecil-kecil jumlahnya yang diserahkan kepada orang miskin, pengemis, pengamen, dan lain-lain. Sedangkan wakaf hampir sama dengan infak, tetapi mempunyai unsur kekekalan manfaatnya; tidak boleh diperjual belikan dan tidak boleh diwariskan (Ridwan al-Makassari, 2006).

Urgensi filantropi dalam Islam dapat dilihat dari cara al- Qur'an menekankan keseimbangan antara mengeluarkan zakat dan menegakkan shalat. Begitu tegasnya perintah mengenai zakat, al-Qur'an mengulang sebanyak 72 kali perintah zakat (ita' az-zakat) dan menggandengkannya dengan perintah shalat (iqam ash-shalat). Kata infak dengan berbagai bentuk derivasinya muncul sebanyak 71 kali dan kata sedekah muncul sebanyak 24 kali yang menunjukkan arti dan aktivitas filantropi Islam. Ajaran shalat merupakan rukun Islam yang utama dan pengamalan zakat dinilai setara dengan pelaksanaan shalat (QS. al-Baqarah: 177).

Dengan memperhatikan penjabaran tersebut, Visi, Misi, Tujuan dan sasaran lembaga filantropi islam akan lebih terarah yang selanjutnya dituangkan dalam fungsi fungsi manajemen.

\section{Fungsi Planning (Perencanaan)}

Perencanaan pengelolaan dana lembaga filantropi islam dibuat harus berdasarkan data data aktual untuk bahan penyusunan perkiraan-perkiraan atau asumsi-asumsi masa yang akan datang jalan menggambarkan dan merumuskan kegiatan-kegiatan yang diperlukan untuk pengembangan ekonomi umat. 
Fungsi O rganizing ( Pengorganisasian )

Pengorganisasian ialah penentuan, pengelompokkan, dan penyusunan macam-macam kegiatan yang diperlukan dalam pengelolaan dana lembaga filantropi islam untuk pengembangan ekonomi umat, penempatan orang-orang, terhadap kegiatan-kegiatan ini, penyediaan faktor-faktor physik yang cocok bagi keperluan kerja dan penunjukkan hubungan wewenang, yang dilimpahkan terhadap setiap orang dalam hubungannya dengan pelaksanaan pengelolaan dana lembaga filantropi islam dalam suatu bagan struktur organisasi yang dirancang sesuai kebutuhan kerja. Dalam pengorganisasian Menurut Terry hendaknya berpedoman pada azas azas organisasi yaitu : (1) The Objective (adanya tujuan); (2) Departementation (pembagian kerja); (3) A ssign The Personel (penempatan tenaga kerja); (4) A uthority and Responsibility (wewenang dan tanggungjawab) dan (5) Delegation Of A uthority (pendelegatian wewenang)

Fungsi A ctuating (Penggerakan )

Tercapainya tujuan bukan hanya tergantung kepada planning dan organizing yang baik, melainkan juga tergantung pada penggerakan dan pengawasan. Perencanaan dan pengorganisasian hanyalah merupakan landasan yang kuat untuk adanya penggerakan yang terarah kepada sasaran yang dituju. Penggerakan tanpaplanning tidak akan berjalan efektif karena dalam perencanaan itulah ditentukan tujuan, budget, standard, metode kerja, prosedur dan program. Faktor-faktor yang diperlukan untuk menggerakan menurut G.R Terry alih bahasa Winardi (2007) yaitu: (1) Leadership (Kepemimpinan); (2)A ttitude and morale(Sikap dan moril); (3)Communication (Tatahubungan); (4) Incentive (Perangsang); (5) Supervision (Supervisi); (6)D iscipline (Disiplin).

\section{Keempat, Controlling (Pengawasan)}

Pengawasan dapat dirumuskan sebagai proses penentuan apa yang harus dicapai yaitu standard, apa yang sedang dilakukan yaitu pelaksanaan, menilai pelaksanaan, dan bilamana perlu melakukan perbaikan-perbaikan, sehingga pelaksanaan sesuai dengan rencana, yaitu selaras dengan standard (ukuran). Proses pengawasan sebagai berikut, yaitu: (1) D etermining the standard or basis for control (menentukan standard atau dasar bagi pengawasan); (2) M easuring the performance (ukuran pelaksanaan); (4) Comparing performance with the standard and ascerting the difference, it any (bandingkan pelaksanaan dengan standard dan temukan jika ada perbedaan) : (5) Correcting the deviation by means of remedial action (perbaiki penyimpangan dengan cara-cara tindakan yang tepat).

Pengel olaan D ana Lembaga Filantropi Islam D alam Pengembangan Ekonomi U mat

Filantropi berdasarkan sifatnya dapat dikelompokkan menjadi dua, yaitu tradisional dan keadilan sosial. Dalam filantropi tradisional, praktiknya dapat berbentuk pemberian yang besifat langsung untuk kepentingan pelayanan sosial, misalkan pemberian sumbangan langsung dari dermawan untuk masyarakat yang membutuhkan. Pemberian ini lebih ditujukan untuk memenuhi kebutuhan sehari-hari, seperti makanan dan minuman, dan atau berbentuk uang. Bentuk filantropi kedua adalah filantropi keadilan sosial, yang lebih berfungsi untuk mengurangi disparitas kemiskinan (atau perbedaan yang jauh antara si kaya dan si miskin). Filantropi jenis ini lebih ditujukan untuk menyelesaikan maslaah kemiskinan melalui akar masal ahnya, misalnya dari sisi ketidakadilan dalam alokasi sumber daya dan akses kekuasaan dalam masyarakat. 
Konsep filantropi dalam islam diwujudkan dengan aktivitas zakat, infaq, shadaqah dan wakaf. Pentingnya masalah ini sudah disadari oleh khalifah Abu Bakar di masa kepemimpinannya. Beliau melihat bahwa kepentingan filantropi islam yaitu zakat merupakan sebagai salah satu dari tiang agama yang harus dilaksanakan. di masa itu, bagi orang-orang yang tidak membayar zakat maka akan diperangi olehnya. di Indonesia, aturan mengenai zakat, infaq, shadaqah serta wakaf telah didukung oleh fatwa-fatwa ulama serta undang-undang di Indonesia. Kondisi ini menjadikan peran lembaga-lembaga filantropi islam dalam pengumpulan dan pengalokasian dana sosial memiliki legitimasi dari pemerintah sehingga upaya untuk memaksimalkan peran mereka dalam ekonomi umat terus didorong. Peran strategis lembaga filantropi islam di Indonesia perlu diwujudkan secara masif, melalui sosialisasi yang secara luas dapat menjangkau seluruh lapisan masyarakat. Maksimalisasi dalam pengumpulan zakat ini diharapkan dapat memperkuat peran lembaga filantropi untuk berkontribusi lebih besar lagi dalam mengentaskan permasalahan sosial di masyarakat, seperti pendidikan dan kemiskinan.

Untuk memaksimalkan peran tersebut, diperlukan langkah-langkah strategis dalam upaya meningkatkan kesadaran masyarakat dan efektivitas lembaga filantropi melalui tindakan: Pertama, pihak terkait terus melakukan upaya edukasi dan sosialisasi kepada masyarakat tentang pentingnya sikap filantropi sebagai wujud dari aplikasi nilai-nilai agama untuk meraih kebahagiaan hidup dunia akhirat. Sarana filantropi dalam Islam, seperti kesadaran berzakat, berinfaq, bershadaqah, dan berwakaf memerlukan penguatan dan penataan melalui manajemen modern, teknologi dan sistem pengelolaannya diperbaiki untuk mencapai hasil pengembangan ekonomi umat dan berdampak terhadap kehidupan masyarakat luas.

Kedua, phak terkait perlu menguatkan peran dan manfaat badan atau lembaga yang bergerak di bidang filantropi, seperti Baznas, LAZ, dan yang lainnya agar semakin dipercaya oleh masyarakat. Lembaga-lembaga tersebut harus dikelola dengan transparan, efektif dan efisien melalui manajemen yang baik. Ketiga, pihak terkait perlu memperluas pemanfaatan dana filantropi, tidak hanya untuk hal-hal yang bersifat konsumtif dan sesaat, namun juga dapat menjangkau kegiatan jangka panjang seperti pendidikan dan bantuan usaha yang terus didampingi perkembangannya melalui pelatihan dan penyediaan inkubator usaha dan kewirausahaaan. Keempat, pihak terkait perlu mengembangkan kerjasama dengan berbagai pihak, termasuk sektor pendidikan dan bisnis. Upaya ini dapat dilakukan melalui serangkaian kegiatan kerjasama antara lembaga untuk mewujudukan gerakan filantropi ini menjadi gerakan pengembangan ekonomi umat bersama yang bersifat masif.

Dalam Kongres U mat Islam Indonesia ke-6 di Yogyakarta yang dilaksanakan tahun 2015 membahas isu penting untuk merumuskan dan memberikan rekomendasi untuk menguatkan peran ekonomi umat Islam. Langkah ini dilakukan atas kesadaran pada perlunya langkah nyata untuk mengatasi kemiskinan dan ekonomi masyarakat muslim di tengah globalisasi dan pasar bebas sekarang ini. Filantropi Islam perlu diperkuat dan dijadikan kontributor dalam pengembangan ekonomi umat di Indonesia.

Potensi filantropi umat islam terwujud dalam bentuk Zakat, Infaq, Shadaqoh,dan Wakaf (ZISWAF), yang merupakan bukti keimanan dan kecintaan seorang muslim yang melakukannya terhadap perbuatan baik sehingga dapat membawa keberuntungan dunia dan akhirat seperti dijelaskan dalam Surat At-Taubah (9) ayat 60 dan 103, Surat AI- Baqarah (2) ayat 177 dan 261, Surat Ali Imron (3) ayat 133 dan 134, Surat AI-Fathir (35) ayat 29 dan 30 serta sejuml ah ayat ayat lainnya dalam Al Qur'an. Hal ini menunjukan bahwa Filantropi merupakan ibadah, ibadah maaliyah ijtimaiyyah yaitu ibadah dibidang harta yang memiliki posisi sosial sangat penting dan menentukan pengembangan ekonomi umat. 


\section{Kesimpulan}

Kesimpulan

Islam sebagai agama yang rahmatan lil alamin memberikan banyak pandangan kepada seluruh manusia dalam melaksanakan kehidupannya. Dalam bidang ekonomi Islam tidak memposisikan aspek materi sebagai bentuk tujuan dari proses aktivitas ekonomi. Oleh karena itu, pencapaian dan tujuan ekonomi dalam Islam yakni tercapainya falah, berasal dari A falahaYuflihu artinya kesuksesan, kemuliaan dan kemenangan. Kemuliaan multidimensi dengan menjalankan aktvitas ekonomi tidak mengorientasikan diri pada pencapaian materi belaka, melainkan juga pencapaian spiritual. Jika tidak terjadi keseimbangan tujuan tersebut, maka mengakibatkan beberapa dampak seperti kesenjangan sosial, manipulasi, kemiskinan dan lainnya. Ketidakseimbangan dalam kaitannya dengan dengan kemiskinan dapat diselesaikan dengan adanya kedermawanan ataupun filantropi. Kini aktivitas filantropi Islam saat ini menjadi perhatian banyak pemikir, akademisi dan praktisi.

Hal tersebut dikaitkan dengan penyalurannya filantropi Islam dalam hal ini ZISWAF,yang masih banyak bergerak dalam wilayah kegiatan bakti sosial, bantuan karitas, santunan anak yatim, pembangunan Madrasah danlainnya. Bahkan cenderungmengabaikan kepentingan umat Islam lainnya seperti, bantuan hukum, perlindungan anak, advokasikebijakan publik, pemberdayaan perempuan dan beberapa agenda penting lainnya, masih kurang mendapatkan support dari pendayahgunaan dana filantropi disamping upaya ingin mengetahui potensi filantropi Islam dan dampaknya bagi pengembangan ekonomi umat,terutama masyarakat miskin atau kaum dhuafa.

Implikasi

Peran filantropi Islam, seperti zakat, infak, sedekah dan wakaf (Ziswah) dapat dijadikan sebagai instrumen utama untuk mengatasi masalah sosial seperti kemiskinan. Selain itu, pengelolaan yang didasarkan pada transparansi, efektif dan efisien perlu didorong untuk meningkatkan kepercayaan umat. Dari sisi pemerintah, upaya yang dapat dilakukan adalah dengan cara memfasilitasi tumbuh-berkembangnya lembaga filantropi, termasuk lembaga keuangan syariah dalam skala kecil, mikro dan menengah. Kerjasama dan singeri lintas instansi perlu dilakukan dengan mengajak semua sektor seperti pendidikan dan sektor bisnis untuk memiliki andil sebagai komponen penting dalam pengentasan kemiskinan dan wujud dari semangat amal jama'i. Pranata sosial dan infrastruktur perekonomian umat, seperti perbankan syariah dan lembaga keuangan mikro syariah perlu diperkuat pengelolaannya melalui dukungan sistem dan tata kelola yang baik, serta lembaga pengelola zakat dan wakaf, seperti Badan A mil Zakat Nasional, lembaga-lembaba amil zakat yang dibentuk atas swadaya masyarakat, Badan Wakaf Indonesia dan lainnya harus didorong untuk menjadi kekuatan besar dalam rangka pengembangan ekonomi umat yang efektif. Konsistensi penerapan regulasi, peningkatan kapasitas organisasi melalui dukungan sumber daya manusia yang baik dan teknologi, serta akuntabilitas lembaga filantropi sebagai pengelola amanah dan dana masyarakat perlu diperkuat.

\section{Keterbasan}

Studi ini menggunakan pendekatan kajian terbatas mengenai literatur terkait dengan pengelolaan ZISWAF dari sisi manajemen dan kemanfaatannya untuk ekonomi umat. Penelitian mendatang perlu melakukan studi lapangan untuk mempelajari aspek manajemen dari lembaga 
pengelola ZISWAF, sekaligus melakukan evaluasi dan perbaikan untuk meningkatkan kemanfaatan dari lembaga bagi ekonomi umat secara luas.

\section{Daftar Pustaka}

A bu Bakar, Irfan dan Chaidar S. Bamualim (ed.). (2006). Filantropi Islam dan Keadilan Sosial: Studi tentangPotensi, Tradisi, dan Pemanfaatan Filantropi Islam di Indonesia, kerjasama The Ford Foundation dan CSRC.

AI-Makassari, R. (2006). Pengarusutamaan Filantropi Islam untuk Keadilan Sosial di Indonesia; Proyek yang Belum Selesai: Jurnal Galang.

al-Mubarok, F., \& Muslim, A. B. M. B. (2020). KESALEHAN SOSIAL MELALUI PENDIDIKAN FILANTROPI ISLAM. JIEBA R: Journal of I slamic Education: Basic and A pplied Research, 1(1), 115.

Ash Shiddiqie, T.M.H (2007). P edoman Z akat,Semarang: PT Pustaka Rizki Putra.

Athoillah, A. (2010). Dasar-dasar manajemen. Bandung: Pustaka Setia.

Bamualim, C. S. dan Abu Bakar., I (ed.). (2005). Revitalisasi Filantropi Islam: Studi Kasus LembagaZ akat dan Wakaf di Indonesia, Jakarta: Pusat Bahasa dan Budaya (PBB) UIN Jakarta

Badan Amil Zakat Nasional (2016). Potensi Zakat di Indonesia. Retrieved from http/ id.m.wiki pedia,org/ BAZNAS.

Hafidhudin, D. (2017). Pemerintah Terus Mendorong dan Memfasilitasi Tumbuh Berkembangnya Lembaga Filantropi. Retrieved from https/ / Republika.co.id, accessed 12 Dec 2019.

Fauzia, A (2013). Filantropi islam sejarah dan kontestasi masyarakat sipil dan negara di Indonesia. Yogyakarta: Gading Publishing.

Futaqi, S., \& Machali, I. (2018). Pembiayaan Pendidikan Berbasis Filantropi Islam: Strategi Rumah Pintar BAZNAS Piyungan Yogyakarta. M A N A GERIA : Jurnal M anajemen Pendidikan Islam, 3(2), 231-256.

Kasdi, A . (2016). Filantropi Islam Untuk Pemberdayaan Ekonomi Umat (Model Pemberdayaan ZISWAF di BMT Se-Kabupaten Demak). Iqtishadia: Jurnal Kajian Ekonomi dan Bisnis Islam STAIN Kudus, 9(2), 227-245.

Terry, G.R (2007). Principles Of M anagement Eigth Edition, Bandung: terjemahan indonesia pada Penerbit Alumni.

Hasibuan, M .S.P (2014). M anajemen dasar pengertian dan masalah, Jakarta : Bumi Aksara,.

Ilchman, W.F., Stanley N. K, dan Edward L. Queen II (ed.). (2006). Philanthropy in the World Traditions(Filantropi di Berbagai Tradisi D unia), Jakarta: Center for the Study of Religion and Culture (CSRC)

Klein, K (2001). Fundraising for Social Change, Fourth Edition, Oakland California: Chardon Press.

Mahfud, C. (2018). Filantropi Islam di Komunitas Muslim Tionghoa Surabaya: Ikhtiar Manajemen Zakat untuk Kesejahteraan dan Harmoni Sosial. INFEREN SI: Jurnal Penelitian Sosial Keagamaan, 12(1), 149-176.

Mardiyah, S. (2018). Manajemen strategi BAZNAS dalam pengelolaan dana filantropi islam. IFinance: a Research Journal on Islamic Finance, 4(1), 64-83.

Muhammad, D. A (2006). Sistem Ekonomi Islam: zakat dan wakaf, Jakarta.U.I

Salman, A.N (2017). Pemberdayaan Lembaga Filantropi Islam di Indonesia. Retrieved from http/ indonesia.tempo.co, (accessed 17 Jan 2020)

Saripudin, U. (2016). Filantropi Islam dan Pemberdayaan Ekonomi. BISNIS: Jurnal Bisnis dan $M$ anajemen Islam, 4(2), 165-185. 
Setyanto, A. W. E. (2016). Tradisi Persenan Bagi Pedagang Pracangan di Pasar Legi Songgolangit Ponorogo Dalam Perspektif Filantropi Islam. M uslim H eritage, 1(1), 37-58.

Sudiyo, S., \& Fitriani, F. (2020, January). Lembaga Ziswaf Sebagai Lembaga Filantropi Islam dan Pemberdayaan Masyarakat Di Kota Bandar Lampung. In Prosiding Seminar Nasional Pengembangan Teknologi Pertanian.

\section{A bout A uthors}

Deden Gandana Madjakusumah dan Udin Saripudin adalah dosen di Pascasarjana Universitas Islam Bandung

Accepted author version posted online: 30 April 2020

$$
\text { (c) (1) }
$$

(C) 2020 The Author(s). This open access article is distributed under a Creative Commons Attribution (CC-BY) 4.0 license 